\title{
Nutrition During the Early Rearing Period Affects the Incidence of Wooden Breasts in Broilers
}

\author{
Tomohito Iwasaki ${ }^{1}$, Takafumi Watanabe ${ }^{2}$, Yasuhiro Hasegawa ${ }^{1}$, Marina Hosotani ${ }^{2}$ and Takeshi Kawasaki ${ }^{3}$ \\ ${ }^{1}$ Department of Food Science and Human Wellness, College of Agriculture, Food and Environment Science, \\ Rakuno Gakuen University, Ebetsu, 069-8501, Japan \\ ${ }^{2}$ Department of Veterinary Anatomy, School of Veterinary Medicine, Rakuno Gakuen University, Ebetsu, 069-8501, Japan \\ ${ }^{3}$ Research Office Concerning the Health of Humans and Birds, Abashiri, 099-3119, Japan
}

This study aimed to evaluate the relationship between early nutrition and the incidence of wooden breasts (WB) in broilers. Sixteen male and twenty female neonatal ROSS 308 broiler chicks were divided equally into four flocks. From 0-12 days of age, starter diet $\mathrm{H}$, composed of $22.4 \%$ crude protein $(\mathrm{CP}), 6.6 \%$ crude fat (CF), $1.25 \%$ lysine, $0.48 \%$ methionine, and $\geq 3,070 \mathrm{kcal} / \mathrm{kg}$ metabolizable energy (ME), was fed to two flocks, and starter diet $\mathrm{L}$, composed of $19.9 \% \mathrm{CP}, 2.5 \% \mathrm{CF}, 1.04 \%$ lysine, $0.38 \%$ methionine, and $\geq 2,930 \mathrm{kcal} / \mathrm{kg} \mathrm{ME}$, was fed to the remaining two flocks. All the flocks were fed the same commercial finisher diet, composed of $20.3 \% \mathrm{CP}, 7.5 \% \mathrm{CF}$, $1.18 \%$ lysine, $0.44 \%$ methionine, and $\geq 3,300 \mathrm{kcal} / \mathrm{kg} \mathrm{ME}$, from $12-47$ days of age. The birds were weighed every 2-5 days, subjected to a wing-lift test, and histology was conducted on the pectoralis major muscle tissue samples from all the birds necropsied at 47 days of age. Significant differences in the mean body weight between groups H and $\mathrm{L}$ were observed during 6-16 days and 24-26 days of age in males and during 6-26 days of age in females. Regarding the score evaluation of the individual lesions reflecting wooden breast, the birds in which back-to-back wing contact was not possible had higher lesion scores than those in which back-to-back wing contact was possible. The absence of back-to-back wing contact appeared more frequently in flocks fed the starter diet L, particularly in males. These results indicate that inappropriate nutrition levels in the starter diet increase the incidence of WB. Therefore, avoiding early nutrition deficits is a cost-effective feeding strategy.

Key words: broiler, lesion score, nutrition, starter diet, wing contact, wooden breast

J. Poult. Sci., 58: 177-185, 2021

\section{Introduction}

In the broiler industry, rapid weight gain and higher yields in chickens are associated with an improved meat production efficiency. However, on occasion, rapid weight gain can lead to an increased incidence of various health disorders during the broiler rearing period (Julian, 1998). In particular, a fast initial growth rate can lead to increases in issues concerning rearing management, such as the incidence of metabolic disorders (Afsharmanesh et al., 2016).

Currently, the major high-yielding broiler lines grow rapidly

Received: April 6, 2020, Accepted: July 20, 2020

Released Online Advance Publication: September 25, 2020

Correspondence: Takeshi Kawasaki, DVM, Ph.D. Research Office Concerning the Health of Humans and Birds, 2-7-1, Masu-ura, Abashiri, 0993119, Japan. (E-mail: takeshi@kawavet.com)

The Journal of Poultry Science is an Open Access journal distributed under the Creative Commons Attribution-NonCommercial-ShareAlike 4.0 International License. To view the details of this license, please visit (https:// creativecommons.org/licenses/by-nc-sa/4.0/). and are capable of reaching over $3 \mathrm{~kg}$ in weight by 45 days of age. Broiler growth rates have increased by over $400 \%$, with a concurrent $50 \%$ reduction in the feed conversion ratio (FCR) from 1957 to 2005 (Zuidhof et al., 2014). In recent years, the incidence of a remarkably hardened pectoralis major muscle, which has a rubber-like texture and is commonly called "wooden breast," has occurred frequently in broilers with rapid growth performance (Sihvo et al., 2014; Kuttappan et al., 2016; Petracci et al., 2019), and it has routinely been detected during the process of cutting and trimming breast fillets in the poultry slaughterhouse. This pectoralis major muscle abnormality causes chronic economic attrition in the broiler industry worldwide, and it is being studied from a variety of angles. Wooden breast syndrome starts as swollen, discolored lesions, which first appear in the most distal region on the cranial aspect and expand to the caudal aspect of the pectoralis major muscles (Abasht et al., 2019). These changes are closely linked to an inability to sufficiently lift wings due to an increase in breast stiffness (Kawasaki et al., 2016). Histologically, observations have 
been made of myofibers of variable diameter, which are devoid of their characteristic polygonality in cross-section, degenerated, or necrotic myofibers, loss of striation, infiltration of inflammatory cells, regenerated myofibers, diffuse thickening of the interstitium with variable amounts of loose connective tissue, fibrosis, and on occasion, perivascular infiltration around veins and splitting myofibers (Sihvo et al., 2014).

In recent years, several studies have focused on restricted feeding to control broiler growth rates properly. Trocino et al. (2015) showed that the incidence of wooden breasts was significantly affected by gender: the incidence in males was two-fold higher than in females. Furthermore, under the same experimental conditions, it has been reported that muscular tissue lesions indicating wooden breasts were observed from around 14 days of age (Radaelli et al., 2017). Meanwhile, Livingston et al. (2019) showed that restricted feeding from 8 to 47 days of age significantly reduced broiler weight. They also indicated that the signs of wooden breasts were less severe in the birds that were subjected to restricted feeding. These studies suggest that the incidence of wooden breasts is affected by the diet restriction strategy when using the same nutritionally balanced diet and that appropriate diet restriction could reduce the incidence of wooden breasts.

As previous studies have shown that wooden breast is expressed during the early stage of rearing (Radaelli et al., 2017; Kawasaki et al., 2018), it was hypothesized that an improvement in feeding during the initial stage of rearing could reduce the incidence of wooden breast syndrome. Therefore, this study aimed to examine the influence of feeding two different starter diets of different nutritional composition on the incidence of wooden breast syndrome in broiler chickens. The findings of this study are important in informing the poultry industry with regard to maximizing the benefits and minimizing the costs of starter diets of different nutritional composition during the early stage of rearing.

\section{Materials and Methods}

\section{Ethics Statement}

All protocols and procedures in animal handling and sampling were approved by the Rakuno Gakuen University Institutional Animal Care and Use Committee (No. DH19A4) in accordance with the Japan Veterinary Medical Association guidelines for industrial animal medicine and the Act on
Welfare and Management of Animals of the Japanese government. Birds were observed and cared for by animalstock technicians daily, and clinical conditions were checked by a poultry veterinarian, as necessary, during the rearing period. Euthanasia was performed gently under anesthesia and the direction of veterinarians.

\section{Flocks, Feeds, and Rearing}

ROSS 308 is a broiler strain that accounts for the majority of broilers produced in Japan in recent years, and the rearing manual for broiler nutrition is supplied by its breeding company, Aviagen. According to the latest nutritional manual for ROSS 308, $3000 \mathrm{kcal} \mathrm{ME}$ and $23 \% \mathrm{CP}$ are recommended in the starter diet. In rearing ROSS 308 broilers, it is generally recommended to feed a starter diet up to 10 days of age, a grower diet from 11-24 days of age and then 3 steps finisher feed to slaughter age as needed (Aviagen, 2019). In this study, the timing of switching the starter diet to the finisher diet was determined to be 12 days old, referring to the current situation in commercial broiler rearing in recent Japan and the nutrition manual.

Thirty-six ROSS 308 day-old chicks (20 males and 16 females) were used in this study. When the broiler chicks hatched in the poultry house at Rakuno Gakuen University, they were removed from the hatching incubator, individual identification numbers were written on each chick's head and foot with a marker pen, and they were weighed. They were divided into four flocks $(\mathrm{V}, \mathrm{W}, \mathrm{X}, \mathrm{Y}$ in order of adjacent rearing compartments) of nine birds, each with an equal weight distribution and sex ratio of four males and five females (Table 1). Flocks V and X (group H) were fed a corn based commercial starter mash diet $(\mathrm{H})$, which was composed of $22.4 \%$ crude protein, $6.6 \%$ crude fat, $1.25 \%$ lysine, $0.48 \%$ methionine, and $\geq 3,070 \mathrm{kcal}$ metabolizable energy $(\mathrm{ME}) / \mathrm{kg}$, from 0 to 12 days of age. Flocks $\mathrm{W}$ and $\mathrm{Y}$ (group L) were fed a corn based commercial starter mash diet (L), which was composed of $19.9 \%$ crude protein, $2.5 \%$ crude fat, $1.04 \%$ lysine, $0.38 \%$ methionine, and $\geq 2,930 \mathrm{kcal}$ $\mathrm{ME} / \mathrm{kg}$, from 0 to 12 days of age. All the flocks were fed the same commercial finisher mash diet, which was composed of $20.3 \%$ crude protein, $7.5 \%$ crude fat, $1.18 \%$ lysine, $0.44 \%$ methionine, and $\geq 3,300 \mathrm{kcal} \mathrm{ME} / \mathrm{kg}$ from 12 to 47 days of age (Table 2).

Each flock was reared in brooder boxes, with $0.55 \mathrm{~m}^{2}$ of floor space, from 0 to 12 days of age, and in a clean $0.55 \mathrm{~m}^{2}$

Table 1. Mean body weight and the coefficient of variation in body weight $(\mathrm{CV} \%)$ of each the neonatal chick flock

\begin{tabular}{llccccc}
\hline \hline \multirow{2}{*}{$\begin{array}{l}\text { Group (by starter diet) } \\
\text { Flock }\end{array}$} & \multicolumn{2}{c}{$\mathrm{H}$} & & \multicolumn{2}{c}{$\mathrm{L}$} \\
\cline { 3 - 6 } \cline { 5 - 6 } Number of chicks & & $\mathrm{V}$ & & $\mathrm{W}$ & $\mathrm{Y}$ \\
Mean body weight (g) & Male & 9 & 9 & & 9 & 9 \\
& Female & 39.5 & 40.5 & & 39.8 & 41.5 \\
& All of the flock & 40.8 & 40.6 & & 40.4 & 40.9 \\
CV\% of body weight in the flock & 6.4 & 5.7 & & 5.8 & 6.8 \\
\hline
\end{tabular}

No significant difference between all groups. 
concrete-floored pen covered with clean, soft sawdust litter from 12 to 47 days of age. The brooder boxes were permanently lit with light bulbs, and natural lighting was used for the pens. Diet and water were offered ad libitum throughout the rearing period. At $0,3,6,9,11,16,19,24,26,30,33$, $37,41,45$, and 47 days of age, all the birds were individually weighed and subjected to a wing-lift test to determine their ability to achieve back-to-back wing contact (Fig. 1).

None of the birds were vaccinated with any vaccine. Using serum collected at 41 days of age, antibodies against infection with the Newcastle disease virus, infectious bronchitis virus, and infectious bursal disease virus were measured using an appropriate enzyme-linked immunosorbent assay (ELISA).

\section{Muscle Tissue Sampling}

At 47 days of age, all birds were injected with $20-30 \mathrm{mg} /$ $\mathrm{kg}$ sodium pentobarbital via the wing vein and euthanized by exsanguination from the cervical artery under full anesthesia before post-mortem investigation. Sodium pentobarbital was injected using a sterilized disposable $2.5 \mathrm{ml}$ syringe with a 23-gauge needle. Muscle tissue samples were cut out from the cranial region of the pectoralis major muscles along the

Table 2. The composition of ingredients on the feed labels

\begin{tabular}{lccc}
\hline \hline & \multicolumn{2}{c}{ Starter diet } & \multirow{2}{*}{ Finisher diet } \\
\cline { 2 - 3 } & H & L & \\
\hline Cereals & 54 & 65 & 64 \\
Vegetable oil residue & 34 & 31 & 24 \\
Animal feed & 5 & - & 6 \\
chaff and bran & 1 & - & - \\
Other & 6 & 4 & 6 \\
\hline
\end{tabular}

Animal fats are included in other items in the starter diet $\mathrm{H}$ and the finisher diet.

Numerical unit is percent. myofibers and fixed in $10 \%$ formalin. These muscle samples were collected from all necropsied birds.

\section{Histological Examinations}

The formalin-fixed muscle tissue samples were trimmed transversally and longitudinally to approximately $5 \mathrm{~mm}$ thickness and embedded in paraffin following routine procedures.

The paraffin-embedded muscle tissues were sliced to a thickness of $3 \mu \mathrm{m}$, dried sufficiently after mounting on glass slides, the paraffin was removed, and then AZAN staining was performed on the muscle tissues. The AZAN-stained muscle tissues were observed using optical microscopy (BX41, Olympus, Tokyo, Japan). The individual lesions in muscle tissues revealed in previous reports by Sihvo et al. (2014) and Kawasaki et al. (2016) were evaluated using a five score index of severity considering the following features in the muscle: myofibers of variable diameter, myofibers devoid of polygonality, splitting fibers, degenerated or necrotic myofibers, loss of striation, infiltration of inflammatory cells in the interstitium, diffuse thickening of the interstitium with loose connective tissues, fibrosis, myofiber degeneration, perivascular inflammatory cell infiltration, and vacuolar myofiber degeneration (Fig. 2).

The evaluation criteria for each lesion were the scores according to the apparent ratio of each lesion to the visual area of the tissue section.

Score 0: No lesion.

Score 1: The lesion occupied less than $10 \%$ of the tissue area. Score 2: The lesion occupied more than $10 \%$ and less than $40 \%$ of the tissue area.

Score 3: The lesion occupied more than $40 \%$ and less than $80 \%$ of the tissue area.

Score 4: The lesion occupied more than $80 \%$ of the tissue area.

To eliminate the influence of prejudice on the evaluation, the histological observation was performed repeatedly in ascending sample number order until the evaluation was
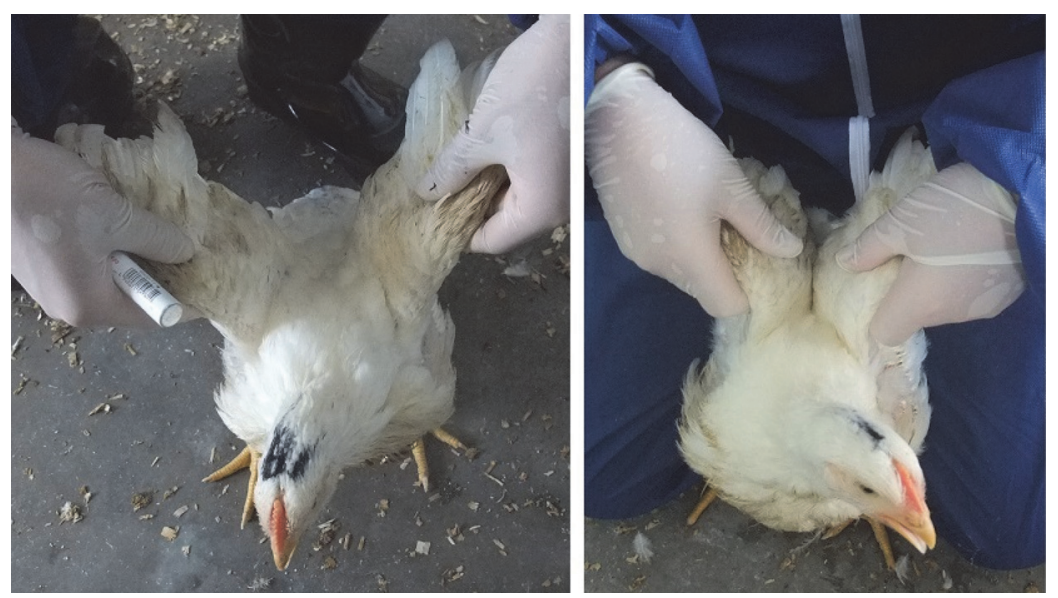

Fig. 1. Wing-lift test to confirm the ability of achieving back-toback wing contact. The left bird is unable to achieve back-to-back wing contact when the wings are lifted, and the right bird can achieve back-to-back wing contact. 

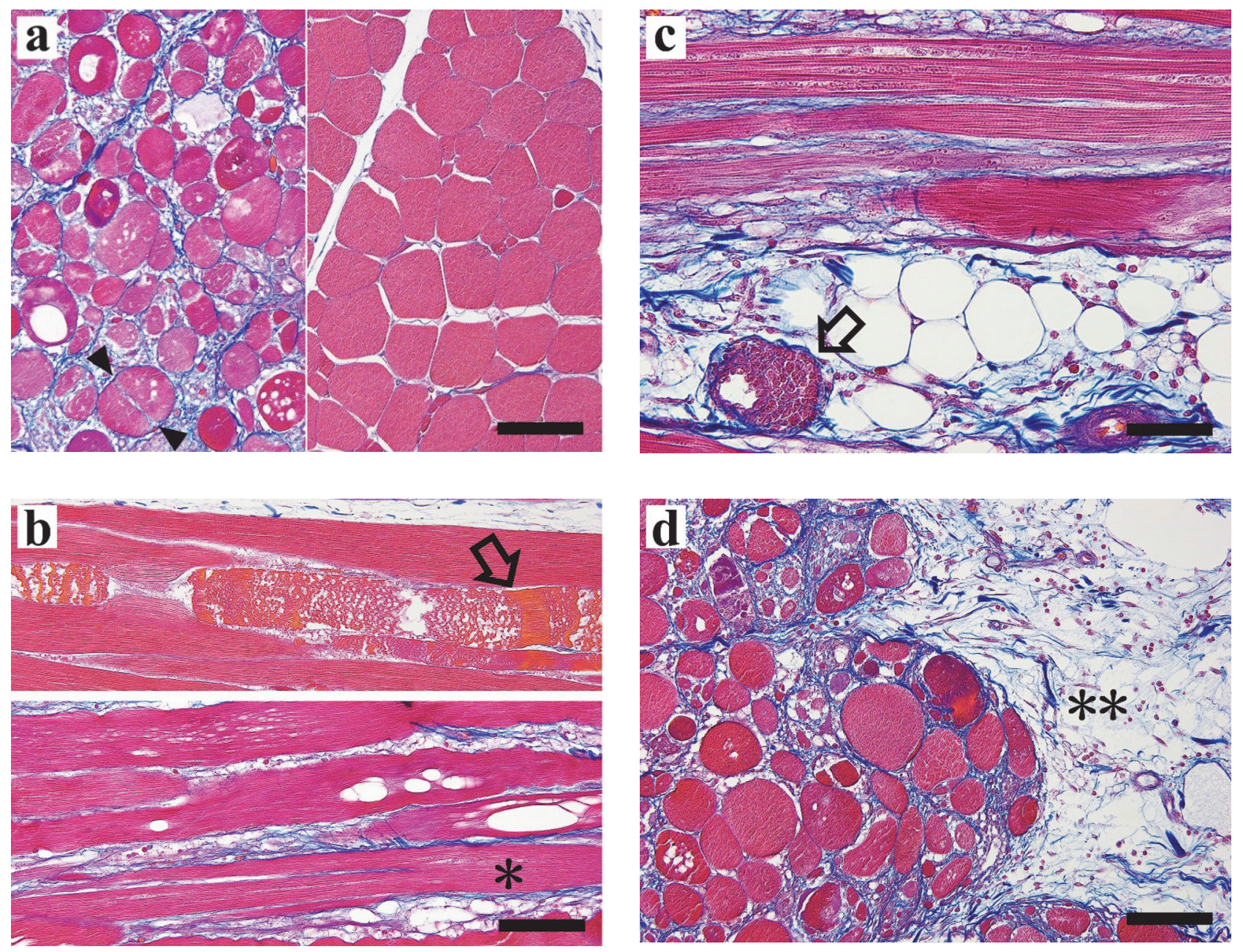

Fig. 2. Representative images of the individual lesions evaluated in muscle tissues. (a) Cross-section of myofibers of pectoralis major muscles. Left: Most myofibers have a round shape due to being devoid of polygonality, and the diameter of myofibers is variable. A splitting fiber is pointed to by two arrowheads. Vacuolar myofibers and some other degenerated fibers are also observed. The interstitium is expanded with fibrosis. Right: Most of the myofibers are polygonal. Small caliber myofibers are observed sporadically in normal muscles. Bar $=100 \mu \mathrm{m}$. (b) Longitudinal section of pectoralis major muscles. Upper: A collapsing hyalinized myofiber that lost the striations in the region pointed to with an arrow. Lower: A splitting fiber $(*)$ and some vacuolar myofibers. Bar $=100 \mu \mathrm{m}$. (c) Muscle regeneration: multinuclear chain myofibers and fusion of myoblasts are observed in the upper half region. The arrow indicates a perivascular inflammatory cell infiltration. Diffuse inflammatory cell infiltration is seen slightly in the interstitium. Bar $=50 \mu \mathrm{m}$. (d) Diffuse thickening with loose connective tissues in the perimysium region $(* *)$. The endomysium region has progressive fibrosis. Diffuse inflammatory cell infiltration is seen in the loose connective tissues. Bar $=100$ $\mu \mathrm{m}$.

complete, after which evaluation scores were sorted according to differences in diet and gender.

\section{Statistical Analysis}

The differences in the daily variations in body weight distribution between flocks was analyzed using the TukeyKramer test. The differences in the scores for each histologic lesion between sex and groups $(\mathrm{H}$ and $\mathrm{L})$ were analyzed using the Steel-Dwass test. To analyze the relationship between wing contact ability and distribution of each lesion score, the Wilcoxon rank sum test was performed. All statistical analyses were performed with $\mathrm{R}$ version 3.6.3 ( $\mathrm{R}$ foundation, 2020). 
Table 3. The mean body weight and the coefficient of variation in body weight (CV\%) of $\mathrm{H}$ group and $\mathrm{L}$ group at each days of age

\begin{tabular}{|c|c|c|c|c|c|c|c|c|}
\hline \multirow[b]{3}{*}{ days of age } & \multicolumn{4}{|c|}{ male } & \multicolumn{4}{|c|}{ female } \\
\hline & \multicolumn{2}{|c|}{$\mathrm{H}$} & \multicolumn{2}{|c|}{$\mathrm{L}$} & \multicolumn{2}{|c|}{$\mathrm{H}$} & \multicolumn{2}{|c|}{$\mathrm{L}$} \\
\hline & mean $(\mathrm{g})$ & $\mathrm{CV} \%$ & mean $(\mathrm{g})$ & $\mathrm{CV} \%$ & mean $(\mathrm{g})$ & $\mathrm{CV} \%$ & mean $(\mathrm{g})$ & $\mathrm{CV} \%$ \\
\hline 0 & 40 & 4.5 & 41 & 7.2 & 41 & 6.8 & 41 & 5.6 \\
\hline 3 & 67 & 7.3 & 65 & 11.0 & 72 & 15.1 & 69 & 6.8 \\
\hline 6 & $127^{\mathrm{a}}$ & 8.7 & $103^{b}$ & 14.6 & $126^{\mathrm{a}}$ & 19.6 & $101^{\mathrm{b}}$ & 11.3 \\
\hline 9 & $234^{\mathrm{a}}$ & 8.1 & $184^{\mathrm{bc}}$ & 17.7 & $225^{\mathrm{ab}}$ & 18.6 & $173^{\mathrm{c}}$ & 13.1 \\
\hline 11 & $303^{\mathrm{a}}$ & 8.5 & $231^{b c}$ & 16.9 & $284^{\mathrm{ab}}$ & 18.6 & $217^{\mathrm{c}}$ & 14.2 \\
\hline 16 & $558^{\mathrm{a}}$ & 8.2 & $405^{\mathrm{bc}}$ & 18.8 & $489^{\mathrm{ab}}$ & 18.1 & $368^{\mathrm{c}}$ & 14.3 \\
\hline 19 & $763^{\mathrm{a}}$ & 9.3 & 611 & 26.1 & $658^{\mathrm{a}}$ & 17.1 & $507^{\mathrm{b}}$ & 14.4 \\
\hline 24 & $1,240^{\mathrm{a}}$ & 9.7 & $1,000^{\mathrm{bc}}$ & 14.0 & $1,043^{\mathrm{b}}$ & 14.4 & $849^{\mathrm{c}}$ & 12.1 \\
\hline 26 & $1,440^{\mathrm{a}}$ & 9.8 & $1,184^{\mathrm{bc}}$ & 13.2 & $1,215^{\mathrm{b}}$ & 13.2 & $996^{\mathrm{c}}$ & 11.6 \\
\hline 30 & $1,893^{\mathrm{a}}$ & 9.6 & $1,625^{\mathrm{a}}$ & 12.4 & $1,595^{\mathrm{b}}$ & 12.2 & $1,339^{\mathrm{b}}$ & 10.7 \\
\hline 33 & $2,264^{\mathrm{a}}$ & 9.8 & $2,013^{\mathrm{ab}}$ & 10.8 & $1,873^{\mathrm{bc}}$ & 12.0 & $1,630^{\mathrm{c}}$ & 10.1 \\
\hline 37 & $2,601^{\mathrm{a}}$ & 9.2 & $2,536^{\mathrm{a}}$ & 8.9 & $2,181^{\mathrm{b}}$ & 11.7 & $2,033^{\mathrm{b}}$ & 9.1 \\
\hline 41 & $3,085^{\mathrm{a}}$ & 7.6 & $2,985^{\mathrm{a}}$ & 7.5 & $2,552^{\mathrm{b}}$ & 10.1 & $2,372^{\mathrm{b}}$ & 8.2 \\
\hline 45 & $3,456^{\mathrm{a}}$ & 7.0 & $3,319^{\mathrm{a}}$ & 7.3 & $2,820^{\mathrm{b}}$ & 10.1 & $2,636^{\mathrm{b}}$ & 7.6 \\
\hline 47 & $3,721^{\mathrm{a}}$ & 6.5 & $3,603^{\mathrm{a}}$ & 6.6 & $3,011^{\mathrm{b}}$ & 10.6 & $2,868^{\mathrm{b}}$ & 6.6 \\
\hline
\end{tabular}

$\mathrm{H}, \mathrm{L}$; group distinguished by starter feed

${ }_{\mathrm{a}, \mathrm{b}, \mathrm{c}}$ Means with different alphabet superscripts within a row differ significantly $(p<0.05)$.

Table 4. The broiler rearing performance of each flocks

\begin{tabular}{|c|c|c|c|c|c|c|}
\hline \multirow[b]{2}{*}{ Flock } & \multicolumn{2}{|c|}{$\mathrm{H}$} & \multicolumn{2}{|c|}{$\mathrm{L}$} & \multirow{2}{*}{$\frac{\mathrm{H}}{\mathrm{V}+\mathrm{X}}$} & \multirow{2}{*}{$\frac{\mathrm{L}}{\mathrm{W}+\mathrm{Y}}$} \\
\hline & $\mathrm{V}$ & $\mathrm{X}$ & $\mathrm{W}$ & Y & & \\
\hline Mean body weight $(\mathrm{kg}) *$ & 3.32 & 3.33 & 3.24 & 3.15 & 3.33 & 3.19 \\
\hline Number of survived birds at 47 days of age & 9 & 9 & 9 & 9 & 18 & 18 \\
\hline Total consumption of starter diet $(\mathrm{kg})$ & 2.90 & 2.90 & 2.71 & 2.67 & 0.32 & 0.30 \\
\hline Total consumption of finisher feed $(\mathrm{kg})$ & 42.50 & 42.10 & 41.36 & 40.30 & 4.70 & 4.54 \\
\hline FCR & 1.52 & 1.50 & 1.51 & 1.52 & 1.51 & 1.51 \\
\hline Age in days & 47 & 47 & 47 & 47 & 47 & 47 \\
\hline Livability (\%) & 100 & 100 & 100 & 100 & 100 & 100 \\
\hline PEF & 466 & 472 & 457 & 441 & 469 & 449 \\
\hline
\end{tabular}

$\mathrm{H}, \mathrm{L}$; group distinguished by starter feed

$\mathrm{PEF}=($ Livability $\times$ Mean body weight $) /(\mathrm{FCR} \times$ Age in days $) \times 100$

* No significant difference between mean body weight of each flock

\section{Results}

\section{Broiler Rearing Performance}

No significant difference existed between the flocks in their mean body weight and the coefficient of variation percentage $(\mathrm{CV} \%)$ at 0 days of age. From 24-47 days in group $\mathrm{H}$ and $30-47$ days in group L, the mean body weight of males was significantly heavier than that of females (Table $3)$. Significant differences in mean body weight between groups $\mathrm{H}$ and $\mathrm{L}$ were seen from 6-16 days and 24-26 days of age in males and from 6-26 days of age in female (Table 3). For other ages, there was no significant difference in the mean body weight between groups $\mathrm{H}$ and $\mathrm{L}$ per gender. The $\mathrm{CV} \%$ of body weight between groups generally increased until the middle of rearing period and decreased toward slaughter age, but there was no significant difference be- tween group $\mathrm{H}$ and $\mathrm{L}$ per gender (Table 3).

The broiler rearing performance of each flock is shown in Table 4. In groups $\mathrm{H}$ and $\mathrm{L}$, the livability rate at the age of 47 days was $100 \%$. In the two flocks of the $H$ group, $2.90 \mathrm{~kg}$ of the starter diet was consumed by each flock in total (converted to $0.32 \mathrm{~kg}$ per bird) and $42.50 \mathrm{~kg}$ of the finisher diet was consumed in total by flock $\mathrm{V}$ and $42.10 \mathrm{~kg}$ in total by flock X (converted to 4.72 and $4.68 \mathrm{~kg}$ per bird, respectively). In the two flocks of the $\mathrm{L}$ group, $2.71 \mathrm{~kg}$ of the starter diet was consumed in total by flock $\mathrm{W}$ and $2.67 \mathrm{~kg}$ in total by flock Y (converted to $0.30 \mathrm{~kg}$ per bird) and $41.36 \mathrm{~kg}$ of the finisher diet was consumed in total by flock $\mathrm{W}$ and $40.30 \mathrm{~kg}$ in total by flock Y (converted to 4.60 and $4.48 \mathrm{~kg}$ per bird, respectively). The mean body weight at 47 days of age was $3.33 \mathrm{~kg}$ in group $\mathrm{H}(3.32 \mathrm{~kg}$ in flock $\mathrm{V}$ and $3.33 \mathrm{~kg}$ in flock X) and $3.19 \mathrm{~kg}$ in group L (3.24 kg in flock W and 3.15 
$\mathrm{kg}$ in flock Y). The feed conversion ratio (FCR) calculated on the total feed consumption, the number of survived birds, and the total body weight of each group at the age of 47 days was 1.52 in flock $\mathrm{V}, 1.50$ in flock $\mathrm{X}, 1.51$ in flock W, and 1.52 in flock $\mathrm{Y}$. The production efficiency factor (PEF) was 469 in group H (466 in flock V and 472 in flock X) and 449 in group L (457 in flock W and 441 in flock Y).

The antibody tests performed using ELISA at 41 days of age showed that the antibodies against infection with Newcastle's disease virus, the infectious bronchitis virus, and infectious bursal disease virus were under the detected level.

\section{Wing-lift Test}

Except that the inability to achieve back-to-back wing contact (wing contact (-)) was seen in some birds, no significant defects were found in the general health condition of all birds in the rearing period. Wing contact $(-)$ began to appear at 26 days of age (one bird of group $\mathrm{H}$ males) and increased at 30 days of age. At 30 days of age, of the eight males and 10 females in each group, the frequency of occurrence of wing contact $(-)$ was three male birds in group $\mathrm{H}$,

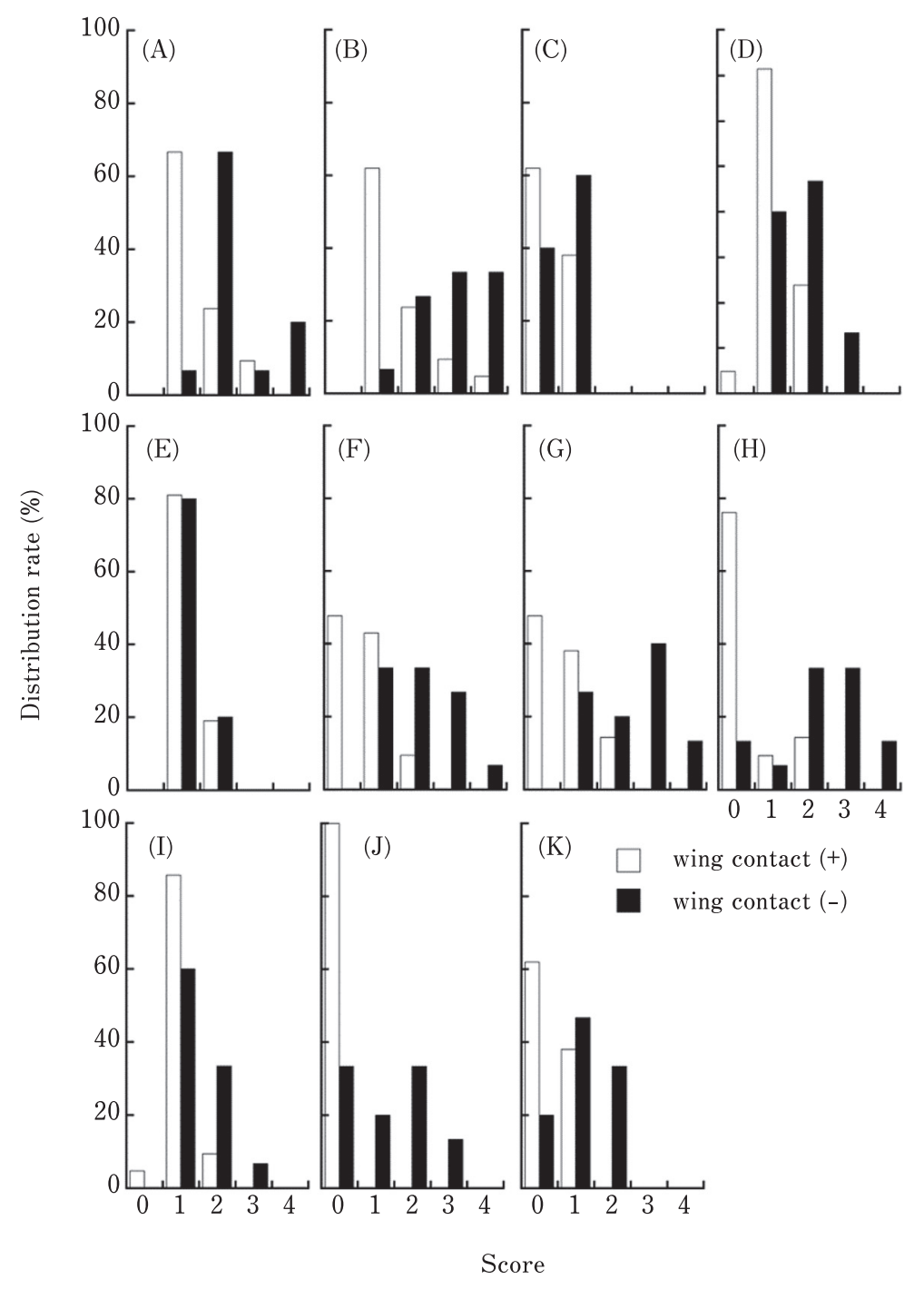

Fig. 3. The distribution of the results of wing-lift test for each histologic lesion score in 47 day old birds. (A) Myofibers of variable diameter, (B) Devoid of myofiber polygonality, (C) Splitting myofibers, (D) Degenerated myofibers, (E) Loss of striation, (F) Infiltration of inflammatory cells in the interstitium, (G) Diffuse thickening of the interstitium with loose connective tissues, (H) Fibrosis, (I) Myofiber regeneration, (J) Perivascular inflammatory cell infiltration, (K) Vacuoles of myofibers.

Score 0: No lesion, Score 1: The lesion occupied less than 10\% of the tissue area, Score 2: more than $10 \%$ and less than $40 \%$ of the tissue area, Score 3: more than $40 \%$ and less than $80 \%$ of the tissue area, Score $4:$ more than $80 \%$ of the tissue area. Total of wing contact $(-)$ birds: $n=15$, and of wing contact $(+)$ birds: $n=21$. 
Table 5. Histological evaluation of lesion scores in broilers fed a high and low nutrient density starter diet

\begin{tabular}{|c|c|c|c|c|c|}
\hline \multirow{2}{*}{\multicolumn{2}{|c|}{ Lesions }} & \multicolumn{2}{|c|}{ male } & \multicolumn{2}{|c|}{ female } \\
\hline & & $\mathrm{H}$ & $\mathrm{L}$ & $\mathrm{H}$ & $\mathrm{L}$ \\
\hline \multicolumn{2}{|c|}{ Myofibers of variable diameter (Small caliber fibers increased) } & $1.9 \pm 0.6$ & $2.6 \pm 1.1$ & $1.4 \pm 0.7$ & $1.6 \pm 0.7$ \\
\hline \multicolumn{2}{|c|}{ Devoid of myofibers polygonality } & $2.8 \pm 1.0^{\mathrm{a}}$ & $2.9 \pm 1.1^{\mathrm{a}}$ & $1.4 \pm 0.7^{\mathrm{b}}$ & $1.8 \pm 1.0$ \\
\hline \multicolumn{2}{|l|}{ Splitting fibers } & $0.4 \pm 0.5$ & $0.6 \pm 0.5$ & $0.6 \pm 0.5$ & $0.3 \pm 0.5$ \\
\hline \multicolumn{2}{|l|}{ Degenerated myofibers } & $1.4 \pm 0.5$ & $1.9 \pm 0.8$ & $1.3 \pm 0.5$ & $1.2 \pm 0.6$ \\
\hline \multicolumn{2}{|c|}{ Loss of striation } & $1.1 \pm 0.3$ & $1.1 \pm 0.3$ & $1.3 \pm 0.5$ & $1.1 \pm 0.5$ \\
\hline \multicolumn{2}{|c|}{ Infiltration of inflammatory cells in the interstisitium } & $1.1 \pm 0.9$ & $2.0 \pm 1.2$ & $0.7 \pm 0.6$ & $1.2 \pm 1.0$ \\
\hline \multicolumn{2}{|c|}{ Diffuse thickening of the interstitium with loose connective tissues } & $1.6 \pm 1.0$ & $2.5 \pm 1.3^{\mathrm{a}}$ & $0.6 \pm 0.7^{\mathrm{b}}$ & $1.1 \pm 0.9$ \\
\hline \multicolumn{2}{|c|}{ Fibrosis } & $1.6 \pm 1.1$ & $2.4 \pm 1.5^{\mathrm{a}}$ & $0.3 \pm 0.6^{\mathrm{b}}$ & $0.7 \pm 0.9$ \\
\hline \multicolumn{2}{|l|}{ Myofiber regeneration } & $1.3 \pm 0.4$ & $1.8 \pm 0.7^{\mathrm{a}}$ & $1.1 \pm 0.3$ & $0.9 \pm 0.3^{\mathrm{b}}$ \\
\hline \multirow[t]{2}{*}{ Perivascular inflammatory cell infiltration } & Vein & $0.5 \pm 1.0$ & $1.5 \pm 1.0^{\mathrm{a}}$ & $0.0 \pm 0.0^{\mathrm{b}}$ & $0.3 \pm 0.6$ \\
\hline & Artely & $0.0 \pm 0.0$ & $0.0 \pm 0.0$ & $0.0 \pm 0.0$ & $0.0 \pm 0.0$ \\
\hline \multicolumn{2}{|l|}{ Vacuolar myofiber degeneration } & $0.9 \pm 0.6$ & $1.4 \pm 0.7^{\mathrm{a}}$ & $0.4 \pm 0.5$ & $0.3 \pm 0.5^{\mathrm{b}}$ \\
\hline
\end{tabular}

Each score value is mean \pm standard deviation.

$\mathrm{H}, \mathrm{L}$; group distinguished by starter feed.

${ }^{\mathrm{a} b}$ Means with different alphabet superscripts within a row differ significantly $(p<0.05)$.

seven male birds in group L, no female birds in group $\mathrm{H}$, and one female bird in group L. At 47 days of age, these numbers were five male birds in group $\mathrm{H}$, seven male birds in group L, no female birds in group $\mathrm{H}$, and three female birds in group L.

\section{Evaluation of Histological Lesions}

The histologic evaluations with lesion scores of muscles are shown in Table 5. The myofiber-devoid polygonality (Fig. 3B) tended to be more frequent in males. Diffuse thickening of the interstitium with loose connective tissues (Fig. 3G), myofiber regeneration (Fig. 3I), perivascular inflammatory cell infiltration (Fig. 3J), and vacuolar myofiber degeneration (Fig. 3K) were significantly more severe in Lgroup males compared to females in $\mathrm{H}$ or $\mathrm{L}$ group. Fibrosis (Fig. 3H) was significantly more severe in H-group males compared to females in $\mathrm{H}$ group. The inflammatory cells that infiltrated the interstitium were mainly composed of heterophils, macrophages, and lymphoid cells. Perivascular infiltrations were lymphocytic, limited around the vein, and were not found around the artery. Lesion scores between same genders showed no significant differences statistically, but in the comparison of the mean scores, L group of the same gender tended to be higher than $\mathrm{H}$ group of same gender. In all samples, splitting fibers were not frequently observed, so the difference in expression rate was not apparent. Degenerated myofibers (Fig. 3D) and infiltration of inflammatory cells in the interstitium (Fig. 3F) were different between samples, albeit not significantly so between groups. Relationship Between Histologic Lesions and the Results of the Wing-Lift Test

The distribution of the wing-lift test against each histologic lesion score in 47-day-old chicks is shown in Fig. 3. No individual was assigned a score of zero for the three lesions; myofibers of variable diameter (Fig. 3A), myofiberdevoid polygonality (Fig. 3B), and loss of striation (Fig. 3E). In all the index lesions, the birds which exhibited back-toback wing contact (wing contact $(+)$ ) had lower lesion scores, while the wing contact $(-)$ birds had higher lesion scores.

The results of the Wilcoxon rank sum test $(p<0.05)$ supported that all lesion score distributions (except splitting fiber and loss of striation) were significantly more severe in wing contact $(-)$ birds than in wing contact $(+)$ birds.

\section{Discussion}

In the histologic evaluation, every wing contact $(-)$ bird exhibited lesions reflecting acute or subacute inflammation (Fig. 3F, G, and J). Fibrosis resulting in chronic injury was observed in the majority of wing contact $(-)$ birds, but some of them were only mildly affected (Fig. $3 \mathrm{H}$ ). These results indicate that the inability to perform back-to-back wing contact is associated with acute or subacute inflammation of the pectoralis major muscles, suggesting that lesions in wooden breasts are essentially acute or subacute myositis. Additionally, perivascular inflammatory cell infiltration was not observed in every wing contact $(+)$ bird but was observed in one-third of the wing contact $(-)$ birds, suggesting that these lesions are a manifestation of the inflammatory changes associated with wooden breasts. Myofiber polygonality, diffuse thickening of the interstitium with loose connective tissues, fibrosis, myofiber regeneration, perivascular inflammatory cell infiltration, and vacuolar myofiber degeneration tended to more severe in males than females. These results indicate that male birds tended to be affected by WB more than female birds, which is consistent with the result in a previous report (Trocino et al., 2015).

Wing contact (-) was first expressed at 26-30 days of age. It then slightly increased to 47 days of age. This clinical symptom was commonly expressed in males, and was especially high in group L males, and most affected birds had developed the symptom by approximately 30 days of age. Previous studies have shown a close relationship between the development of wooden breasts and clinical signs of wing contact (-) (Kawasaki et al., 2016; 2018). In the present 
study, wing contact $(-)$ birds had higher lesion scores than wing contact $(+)$ birds (Fig. 3). These results support that wooden breasts begin to develop at approximately 30 days of age.

The two starter diets used in this experiment significantly differed in their provision of metabolizable energy. Diet $\mathrm{L}$ had a lower amount of crude protein and fat than diet $\mathrm{H}$. These differences in nutritional value caused significant weight differences per gender between the group L and group $\mathrm{H}$ chickens during the rearing period (Table 3). Differences in weight between groups $\mathrm{L}$ and $\mathrm{H}$ during the rearing period may also have been affected by the fact that starter diet consumption in group L was slightly lower than that of group $\mathrm{H}$ (Table 4). Any weight difference during this period was counterbalanced by feeding chickens with a finisher diet after the starter diet (Table 4). Weight at slaughter age was similar, even if a slight weight loss did occur due to nutritional deficiency in the early stages of feeding on the starter diet.

Siegel et al. (1997) revealed that chicks tend to favor highprotein diets in the early rearing period, and with age, favor high-energy diets. This report also showed that feed preference influences the time that chicks spend drinking water and eating. Thus, differences in protein concentration and metabolizable energy between starter diets $\mathrm{H}$ and $\mathrm{L}$ may affect diet preference in chicks, resulting in a slight difference in starter feed consumption. Furthermore, in commercial broiler rearing, infections such as Aviadenovirus (Cowen et al., 1978; Hess, 2013) and Escherichia coli (Kumar et al., 2003), feed contamination by mycotoxins such as Ochratoxin A (Kumar et al., 2003), and excessive heat exposure (Cooper and Washburn, 1998) in the early stages of rearing reduce starter diet consumption. Together with feeding an inadequate starter diet, the factors leading to reduced feed intake during the early stages of feeding can exacerbate broiler wooden breasts. Regarding the relationship between the several factors causing suppression of starter diet consumption and the occurrence of wooden breast, it is necessary to study various conditions in the future. In addition, further research is needed on the optimal nutritional composition and feed morphology of the starter diet.

In conclusion, the findings of this study show that the lack of nutrition in the early stages of rearing can increase the incidence of wooden breasts in broiler chickens. Feed is the largest financial investment in broiler production (Yu et al., 1990), representing $60 \%-70 \%$ of the production cost for most poultry products (Chambers et al., 1983; Leeson and Summers, 2005). Therefore, feeding a nutritious starter diet to avoid inadequate early nutrition is a cost-effective method to reduce the occurrence of wooden breasts.

\section{Conflicts of Interest}

The authors declare no conflict of interest.

\section{Acknowledgments}

The authors would like to thank all staff of the poultry farm of Rakuno Gakuen who cooperated with rearing during the experiment.

This study was supported by a Grant-in-Aid Scientific Research (C) from Japan Society for the Promotion of Science (\#18K05941) (TW) and (\#17K08067) (TI), a Grant-inAid for Cooperative Research Fund (2018-1) from Rakuno Gakuen University, and a research fund from KAWAVET LLC, the owner company of the Research Office Concerning the Health of Humans and Birds.

\section{References}

Abasht B, Zhou N, Lee WR, Zhuo Z and Peripolli E. The metabolic characteristics of susceptibility to wooden breast disease in chickens with high feed efficiency. Poultry Science, 98: 32463256. 2019.

Aviagen. Ross broiler: Nutrition Specifications. 2019.

Afsharmanesh M, Lotfi M and Mehdipour Z. Effects of wet feeding and early feed restriction on blood parameters and growth performance of broiler chickens. Animal Nutrition, 2: 168172. 2016.

Chambers JR, Fortin A and Grunder AA. Relationships between carcass fatness and feed efficiency and its component traits in broiler chickens. Poultry Science, 62: 2201-2207. 1983.

Cooper MA and Washburn KW. The relationships of body temperature to weight gain, feed consumption, and feed utilization in broiler under heat stress. Poultry Science, 77: 237-242. 1998.

Cowen B, Calnek W and Menendez NA. Avian adenoviruses: effect on egg production, shell quality, and feed consumption. Avian Diseases, 22: 459-470. 1978.

Hess M. Aviadenovirus infections. In: Diseases of poultry (Swayne DE, Glisson JR, McDougald LR, Nolan LK, Suarez DL, and Nair V eds.). 13th ed. pp. 290-300. John Wiley \& Sons. USA. 2013.

Julian RJ. Rapid growth problems: ascites and skeletal deformities in broilers. Poultry Science, 77: 1773-1780. 1998.

Kawasaki T, Yoshida $T$ and Watanabe $T$. Simple method for screening the affected birds with remarkably hardened pectoralis major muscles among broiler chickens. Journal of Poultry Science, 53: 291-297. 2016.

Kawasaki T, Iwasaki T, Yamada M, Yoshida T and Watanabe T. Rapid growth rate results in remarkably hardened breast in broilers during the middle stage of rearing: a biochemical and histopathological study. Plos One, 13: e0193307. 2018.

Kumar A, Jindal N, Shukla CL, Pal Y, Ledoux DR and Rottinghaus GE. Effect of ochratoxin A on Escherichia coli - challenged broiler chicks. Avian Diseases. 47: 415-424. 2003.

Kuttappan V, Hargis BM and Owen CM. White striping and woody breast myopathies in the modern poultry industry: a review. Poultry Science. 95: 2724-2733. 2016.

Leeson S and Summer JD. Commercial poultry nutrition. 3rd ed. University Books. Canada. 2005.

Livingston ML, Landon C, Barnes HJ and Brake J. White striping and wooden breast myopathies of broiler breast muscle is affected by time-limited feeding, genetic background, and egg storage. Poultry Science, 98: 217-226. 2019.

Petracci M, Soglia F, Madruga M, Carvalho L, Ida E and M. Estévez. Wooden-breast, white striping, and spaghetti meat: causes, consequences and consumer perception of emerging broiler meat abnormalities. Comprehensive Reviews in Food Science and Food Safety, 18: 565-583. 2019. 
Radaelli G, Piccirillo A, Birolo M, Bertotto D, Gratta F, Ballarin C, Vascellari M, Xiccato $G$ and Trocino A. Effect of age on the occurrence of muscle fiber degeneration associated with myopathies in broiler chickens submitted to feed restriction. Poultry Science, 96: 309-319. 2017.

Siegel PB, Picard M, Nir I, Dunnington EA, Willemsen MHA and Williams PEV. Responses of meat-type chickens to choice feeding of diets differing in protein and energy from hatch to market weight. Poultry Science, 76: 1183-1192. 1997.

Sihvo HK, Immonen K and Puolanne E. Myodegeneration with fibrosis and regeneration in the pectoralis major muscle of broilers. Veterinary Pathology, 51: 619-623. 2014.
Trocino A, Piccirillo A, Birolo M, Radaelli G, Bertotto D, Filiou E, Petracci M and Xiccato G. Effect of genotype, gender and feed restriction on growth, meat quality and the occurrence of white striping and wooden breast in broiler chickens. Poultry Science, 94: 2996-3004. 2015.

Yu MW, Robinson FE, Clandinin MT and Bodnar L. Growth and body composition of broiler chickens in response to different regimens of feed restriction. Poultry Science, 69: 2074-2081. 1990.

Zuidhof MJ, Schneider BL, Carney VL, Korver DR and Robinson FE. Growth, efficiency, and yield of commercial broilers from 1957, 1978, and 2005. Poultry Science, 93: 2970-2982. 2014. 